\title{
A Logistics Enterprises Efficiency Study Based on DEA Model
}

\author{
Lan Shi \\ Guangxi University of Finance and Economics, Guangxi, Nanning 530003 China; \\ 148391071@qq.com
}

Key words: DEA; Logistics industry; Efficiency

\begin{abstract}
The logistics industry is an extremely viable economic hot spots in the rapid economic development environment of China. However, in order to maintain the vitality as well as enhance the core competitiveness of the enterprises, it is necessary for the logistics enterprise to improve efficiency. The foundation of the evaluation of logistics enterprises' efficiency lies in the economic benefit and efficiency. It has practical significance to conduct effective dynamic performance evaluation and analysis on the business data to get the accurately grasp the actual operating level of the enterprise. Both domestic and international practice has proved that using data envelopment analysis (DEA) can get better results on the efficiency evaluation of logistics companies. This study makes simple analysis on the logistics industry in the application of DEA.
\end{abstract}

\section{Introduction}

The logistics industry is an extremely viable economic hot spots in the rapid economic development environment of China, which has made tremendous contribution to promote China's economic development. Meanwhile, with the rapid development of the industry, many constraints as well as problems which have direct impact on the industry is also exposed to be solved.

Efficiency is the fundamental problem of the production, operation and management of the enterprise. Therefore, the foundation of the evaluation of logistics enterprises' efficiency lies in the economic benefit and efficiency. This paper based on the evaluation of the efficiency of logistics enterprises, selected four kinds of original data of 10listed on logistics companies (Namely, fixed assets, main business costs, pay levels and executives total compensation)as the input index, main business profit as the output index. The paper used DEA model to construct efficiency evaluation model of logistics enterprises, analyzed the evaluation results, gave proposals to improve business efficiency.

\section{Efficiency Evaluation Model of Logistics Enterprises Based on DEA}

Introduction to the Basic Model. The basic idea of using DEA to construct evaluation model is: First, determine the basic structural units of the evaluation system- decision making unit DMU, each being evaluated unit can be regarded as a DMU, a plurality of DMU constitute objects to be evaluated. Second, we must determine the effective production frontier, in the other words, to determine the variable evaluate operations by comprehensive evaluation on the weight of each input and output indicators of DMU, and comprehensively analyze of the proportion of inputs and outputs in order to obtain efficient production frontier; Finally, according to every DMU and distance efficient production frontier to judge whether DMU is DEA valid.

DEA model mainly includes: Farrell model, $\mathrm{C}^{2} \mathrm{R}$ model, BCC models, etc. This paper mainly use $C^{2} R$ model as a basic evaluation model. $C^{2} R$ model assumes that the establishment of fraction form in the case of fixed returns to scale linear programming model. Theoretical foundation is efficiency measurement concept of multiple inputs and outputs (Farrell, 1957). This article will select 10 logistics enterprises, there are $\mathrm{N}$ inputs, $\mathrm{M}$ outputs, namely 10 DMU10 $(1 \leq \mathrm{j} \leq 10), \mathrm{Xj}$ and 
$\mathrm{Yj}$ represent vectors of input item and output item respectively. As for the $\mathrm{j}$-enterprises, conduct linear combination of $\mathrm{N}$ item input and $\mathrm{M}$ item output. The $\mathrm{j}$ enterprise's efficiency is the linear combination of the two ratios. This ratio is to between 0 and 1 , the closer the efficiency evaluating value to 0 , the lower degree of efficiency. On the contrary, the closer the value to 1 , the higher degree of efficiency. $\mathrm{C}^{2} \mathrm{R}$ model is as follow:

$$
\begin{array}{ll} 
& \min h_{j}=\theta_{j}-\varepsilon\left(\sum_{r=1}^{s} s_{r j}^{+}+\sum_{i=1}^{m} s_{i j}^{-}\right) \\
\text {s.t. } & \sum_{j=1}^{n} \lambda_{j} X_{i j}+s_{i j}^{-}=\theta_{j} x_{i j} \\
& \sum_{j=1}^{n} \lambda_{j} y_{r j}-s_{r j}^{+}=y_{r j} \\
& \lambda_{i}, s_{r j}^{+}, s_{i j}^{-} \geq 0 ; \quad i=1,2, \Lambda, m ; \quad r=1,2, \Lambda, s ; j=1,2, \Lambda, n
\end{array}
$$

We can easily use the $\mathrm{C}^{2} \mathrm{R}$ model to analyze technical effectiveness of DMU.

Establishment of Evaluation Index System.Logistics enterprise efficiency evaluation index system applied real data combined with DEA method to reflect the operating efficiency of the enterprise. Effective evaluation system of logistics business efficiency is the ultimate goal of logistics enterprise efficiency evaluation. Various types of data indicators in operating can be selected in accordance with the following evaluation principles. The comprehensiveness of the indicators should be taken into consideration when selecting enterprise efficiency evaluation indicators, such as: compared with different periods of the same enterprise; compared with the industry average; compared with competitors, etc. Meanwhile, the comparability of indicators should also take into account, such as, although the indicators are from different companies, but they are generally available. Selection and design of the evaluation indicators should not only clear in concept and meet the need for evaluation purposes, but also consider basic national conditions and other actual situation. It is easier to collect data by using straightforward expressions, which could ensured the standard and reliable measurement results of the index as well as the operability of the evaluation index.

On the basis of existing evaluations of economic efficiency DEA method, when selecting the input and output indicators, we must pay attention that the sum of decision unit should be greater than the sum of the number of indicators, combined with various actual factors that affect the efficiency of logistics enterprises and principles and indicators herein-before. Now the paper use fixed assets, main business cost, and number of employees and executives' total compensation as the input index, operating profit as output index of the evaluation index system. The logistics enterprises' efficiency evaluation model based on DEA as shown in Fig.1.

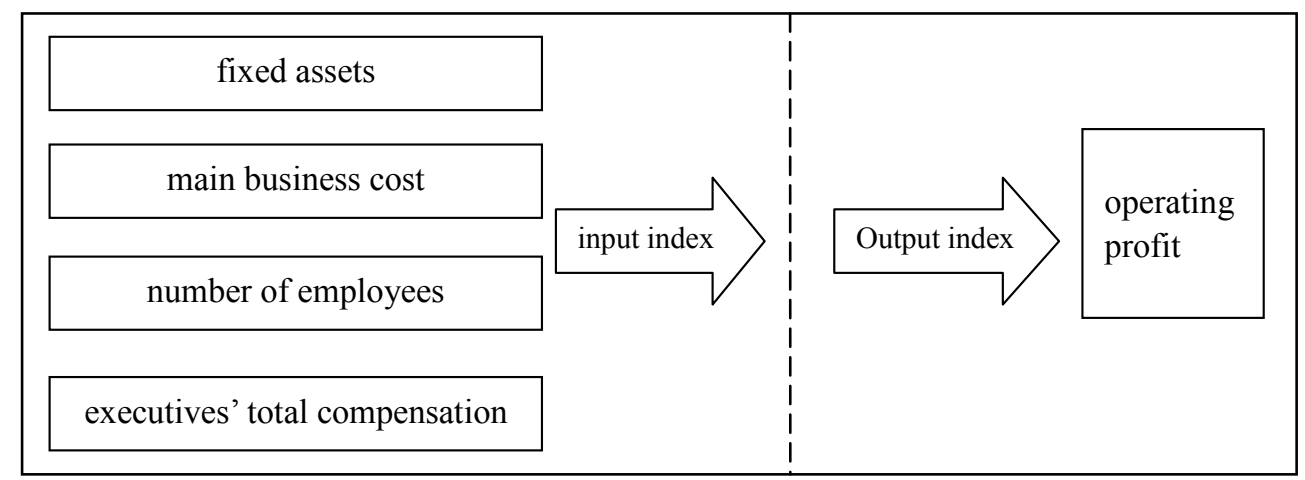

Fig.1 DEA logistics enterprise efficiency evaluation model 


\section{Empirical Study of Logistics Enterprises' Efficiency Based on DEA}

Definition of Efficiency Evaluation. The premise of evaluation of the technical efficiency in this article is the constant returns to scale. Pure technical efficiency and scale efficiency are based on the situation of variable returns to scale. The relationship between the Technical Efficiency (TE),Pure technical efficiency $(\mathrm{PTE})$ and Scale efficiency $(\mathrm{SE}){ }_{\text {is }}{ }^{[5]}$ : TE $=$ PTE $\times$ SE.

Comprehensive Analysis of Enterprises' Efficiency Evaluation.Based on the above mentioned requirements for the selection of decision-making unit (DMU) in DEA method, on the basis of previous research, the author considered the business model, the similarity of accounting data and other aspects, carefully chose 10 logistics companies the Shanghai and Shenzhen Stock Exchange Market as samples. Select total assets, main business cost, number of employees and executives total compensation data from 2010 - 2014 as the input index of DEA method.

According to the above DEA evaluation model, the author input the collected sample enterprises' basic data into the DEA analysis software. (The total value of assets, the main business cost, the number of employees and executives total compensation of sample enterprises from 2010 to 2014 is the policy-making unit DMU). each sample companies' five- years efficiency evaluation value can be obtained by the output of data: Technical efficiency (TE), pure technical efficiency value (PTE), and scale efficiency (SE). Analyze the above calculation results; we can get sample enterprises' TE, PTE, SE value and the average efficiency value of various types of efficiency values (see Table 1). In the five years between 2010 and 2014, 10 sample companies' TE value were $0.5228,0.7129,0.7336,0.7099,0.6919$, TE $2010 \sim 2014<1$, showing the technical inefficiency of the ratio between the ideal investment and the actual investment, and waste of corporate resources exists; TE 2010 2014 $<1$, showing the company is on the middle and upper levels, the overall efficiency still has much room for rectification, efficiency can also be improved significantly. In order to have a more intuitive impression on these data changes, we could put the data in Table. 2 into a diagram, see Fig. 2 。

Table 1 sample enterprises in 2010 2014 and all the various efficiency values mean efficiency value

\begin{tabular}{|c|c|c|c|c|c|c|c|c|c|c|c|c|c|c|c|c|c|c|}
\hline & \multicolumn{3}{|c|}{2010} & \multicolumn{3}{|c|}{2011} & \multicolumn{3}{|c|}{2012} & \multicolumn{3}{|c|}{2013} & \multicolumn{3}{|c|}{2014} & \multicolumn{3}{|c|}{ Annual average } \\
\hline & TE & PTE & SE & $\mathrm{TE}$ & PTE & SE & $\mathrm{TE}$ & PTE & SE & TE & PTE & SE & TE & PTE & SE & TE & PTE & SE \\
\hline China COSCO & 0.297 & 1.000 & 0.297 & 0.384 & 1.000 & 0.384 & 0.401 & 1.000 & 0.401 & 0.429 & 1.000 & 0.429 & 0.308 & 1.000 & 0.308 & 0.3638 & 1.000 & 0.3638 \\
\hline Sinoair & 1.000 & 1.000 & 1.000 & 1.000 & 1.000 & 1.000 & 1.000 & 1.000 & 1.000 & 1.000 & 1.000 & 1.000 & 1.000 & 1.000 & 1.000 & 1.000 & 1.000 & 1.000 \\
\hline Tangshan port & 0.239 & 1.000 & 0.239 & 0.389 & 1.000 & 0.389 & 0.420 & 1.000 & 0.420 & 0.335 & 1.000 & 0.335 & 0.370 & 1.000 & 0.370 & 0.3506 & 1.000 & 0.3506 \\
\hline Tianjin port & 0.660 & 0.709 & 0.930 & 0.764 & 0.782 & 0.976 & 0.602 & 0.685 & 0.879 & 0.719 & 0.822 & 0.875 & 0.748 & 0.906 & 0.826 & 0.6986 & 0.7808 & 0.8972 \\
\hline port of jinzhou & 0.274 & 1.000 & 0.274 & 0.479 & 1.000 & 0.497 & 0.801 & 1.000 & 0.801 & 0.341 & 0.905 & 0.377 & 0.308 & 0.779 & 0.396 & 0.4406 & 0.9368 & 0.469 \\
\hline csdc & 0.303 & 0.325 & 0.931 & 0.392 & 0.399 & 0.982 & 0.722 & 1.000 & 0.722 & 0.862 & 0.965 & 0.894 & 1.000 & 1.000 & 1.000 & 0.6558 & 0.7378 & 0.9058 \\
\hline $\begin{array}{c}\text { Datong Qinhuangdao } \\
\text { railway }\end{array}$ & 0.045 & 0.508 & 0.088 & 1.000 & 1.000 & 1.000 & 1.000 & 1.000 & 1.000 & 1.000 & 1.000 & 1.000 & 1.000 & 1.000 & 1.000 & 0.809 & 0.9016 & 0.8176 \\
\hline Hainan Airlines & 0.717 & 1.000 & 0.717 & 0.809 & 1.000 & 0.809 & 0.541 & 0.774 & 0.699 & 0.513 & 0.715 & 0.717 & 0.399 & 0.732 & 0.546 & 0.5958 & 0.8442 & 0.6976 \\
\hline Baiyun Airport & 0.693 & 1.000 & 0.693 & 0.912 & 1.000 & 0.912 & 0.849 & 1.000 & 0.849 & 0.900 & 1.000 & 0.900 & 0.786 & 1.000 & 0.786 & 0.828 & 1.000 & 0.828 \\
\hline COSCO Shipping & 1.000 & 1.000 & 1.000 & 1.000 & 1.000 & 1.000 & 1.000 & 1.000 & 1.000 & 1.000 & 1.000 & 1.000 & 1.000 & 1.000 & 1.000 & 1.000 & 1.000 & 1.000 \\
\hline Means & 0.5228 & 0.8542 & $\begin{array}{c}0.616 \\
9\end{array}$ & $\begin{array}{c}0.712 \\
9\end{array}$ & $\begin{array}{c}0.918 \\
1\end{array}$ & $\begin{array}{c}0.794 \\
9\end{array}$ & $\begin{array}{c}0.733 \\
6\end{array}$ & $\begin{array}{c}0.945 \\
9\end{array}$ & $\begin{array}{c}0.777 \\
1\end{array}$ & $\begin{array}{c}0.709 \\
9\end{array}$ & $\begin{array}{c}0.940 \\
7\end{array}$ & $\begin{array}{c}0.752 \\
7\end{array}$ & 0.691 & $\begin{array}{c}0.941 \\
7\end{array}$ & $\begin{array}{c}0.723 \\
2\end{array}$ & 0.67422 & $\begin{array}{c}0.9201 \\
2\end{array}$ & $\begin{array}{c}0.7329 \\
6\end{array}$ \\
\hline
\end{tabular}

Observe Fig.2, we could intuitive see the trends and relationship between average technical efficiency $\overline{T E}$, the average pure technical efficiency $\overline{P T E}$, and the average scale efficiency of each year: $\overline{T E}<\overline{S E}<\overline{P T E}$. The average scale efficiency are the lowest of the three average efficiency, 
showing that the overall low efficiency of the sample enterprise is mainly affected by the low scale efficiency. Low Scale efficiency means that companies did not reach close to the ideal state in the allocation of resources, irrational allocation of resources, did not achieve economies of scale. In addition, in the figure we also can clearly see $\overline{T E}<\overline{P T E}$, there is another influencing factor: low pure technical efficiency. PTE indicates that in the case of variable returns to scale, the ratio between ideal investment and actual investment of the enterprise, low pure technical efficiency means that the sample enterprises' expenditure should be adjusted.

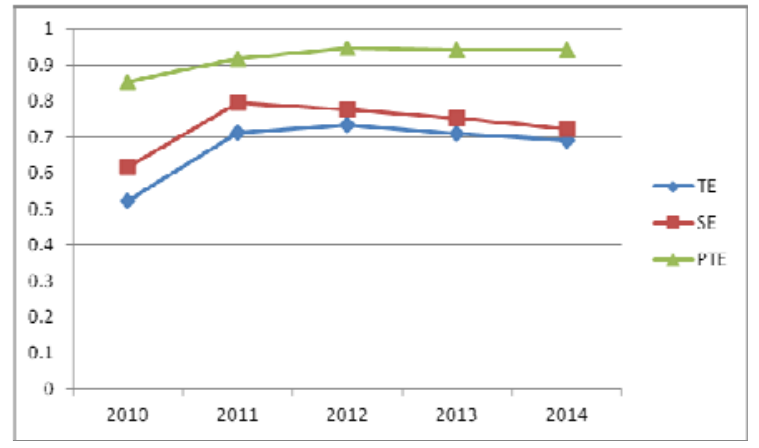

Fig.2 Sample companies all kinds of efficiency of the average change of the curve chart

(1) Technical Efficiency (TE) analysis

Samples from five years of enterprise 'annual average $\overline{T E}_{2010 \sim 2014}, \overline{T E}_{2010 \sim 2014}=0.67422$, from the technology effectively $\mathrm{TE}=1$ still has about $32.58 \%$ amplitude to be improved. Among which, Chinese Ocean, Tangshan Port, Tianjin Port, Jinzhou Port, China Shipping Development, and Hainan Airlines, six companies failed to meet the annual average, accounted for $60 \%$ of the sample enterprises, the proportion is very large. The data shows that the technical efficiency of logistics enterprises is generally low in China. Technical efficiency of the enterprises is invalid; resources are not being fair use. COSCO Shipping and Sinotrans development two companies' technical efficiency TE $=1$ in the five years, which means the two companies' technical efficiency is valid, enterprise production is in a more ideal state.

(2)Pure Technical Efficiency (PTE) Analysis

From the five year sample of enterprises' annual average $\overline{P T E}_{2010 \sim 2014}, \overline{P T E}_{2010 \sim 2014}=0.9212$, which is close to the ideal state of $\mathrm{PTE}=1$, the overall situation of pure technical efficiency is much better. The average value of pure technical efficiency reached the maximum of 0.9459 in 2012 . What's more, China COSCO, Sinotrans Development, Tangshan Port, Baiyun Airport, and COSCO Shipping five companies achieve pure technical efficiency effective. Achieve PTE $=1$ companies accounted for $50 \%$, fully demonstrated that the enterprises' actual investment in management, technology, resources arrangement and other aspects infinitely close to the ideal investment and achieved good results, which can play a more active role in the reference.

In enterprises which failed to realize PTE $=1$, Jinzhou Port and Daqin Railway's PTE annual average has reached more than 0.9. Whereas Tianjin Port, China Shipping Development and Hainan Airlines three companies have relatively low PTE annual average, 0.7808,0.7378,0.8442 respectively. These data show that although the majority of enterprises have not implemented effective pure technical efficiency, but the situation is stable, and can be maintained at a high level. When taking measures to improve the overall technical efficiency, the enterprises can mainly 
concentrate on the other factor SE, then further improve the technical efficiency of enterprises.

(3) Scale Efficiency (SE) Analysis

As already defined before, the relationship among TE technical efficiency, pure technical efficiency PTE and scale efficiency SE is: TE $=$ PTE $\times$ SE. After analysis of,$\overline{T E}_{2010 \sim 2014}$ 、

$\overline{P T E}_{2010 \sim 2014}$, the main factors leading to the low TE value of the sample enterprises is the low SE value. However after observing $\overline{S E}, \overline{S E}_{2010 \sim 2014}=0.73296$, the value is not low. After Further observation, there are still two enterprises- Sinotrans development and COSCO Shipping achieve efficient scale efficiency ( $\mathrm{SE}=1$ ) in five years; Tianjin Port, China Shipping Development, Daqin railway, and Baiyun Airport 4 enterprises' scale efficiency annual average reached over 0.8, the overall level of efficiency reached middle level, accounting for $40 \%$ of the sample enterprises, indicating that there are still room for improvement for scale efficiency stability. However, China COSCO, Tangshan Port, Jinzhou Port and Hainan Airlines four enterprises' scale efficiency annual average is low. The most serious is the China COSCO and Tangshan Port; barely break 0.3 from 2010 to 2014. Scale efficiency has a wide gap between other enterprises. Great efforts should be added to the rectification in order to achieve scale economy. The data of the scale efficiency value shows that logistics business efficiency is uneven in China. Notwithstanding the rapid development momentum, there are still many problems exposed to be solved.

In these sample enterprises, in addition to the Sinotrans development and COSCO Shipping which achieved overall efficiency. Tianjin Port's business situation is different from other enterprises.

Careful observation on each raw data and output efficiency value of Tianjin Port could found out that Technical Efficiency is not valid in the five years. In Year 2010 - 2014 pure technical efficiency were lower than scale efficiency value (PTE $<$ SE), indicating purely technical inefficiency is the main cause of technical inefficiency. However, according to PTE2014=0.906 > SE2014 $=0.826$, Pure technical efficiency value exceeds the scale efficiency, showing that scale efficiency of Tianjin Port has changes but meaningless. Adjustments had been made in Tianjin Port to improve the pure technical efficiency is meaningless. The enterprise should consider adjusting the scale of operation in order to achieve economies of scale.

\section{Conclusion}

This paper used the DEA $\mathrm{C}^{2} \mathrm{R}$ Model to perform quantitative analysis on 10 participating logistics enterprises' various input and output data, Discussed technical efficiency, pure technical efficiency and scale efficiency of 10 participating logistics enterprises under fixed scale returns condition from 2010 to 2014, tried to evaluate the efficiency of logistics companies. We made the following conclusions:

(1) The technical efficiency of China's logistics industry in general is low.

(2) China's logistics enterprises cannot all achieve technical efficiency, wherein the scale inefficiency is the main reason for technical inefficiency of logistics enterprises. Some enterprises also influenced by pure technical inefficiency. Enterprises can adjust production techniques in order to achieve the purpose of effective technical efficiency.

(3) In order to make enterprises' technology efficient, we should adjust the size of the enterprise to achieve economy of scale, thus, achieving enterprises' technical efficiency.

(4) When enterprise reached technical efficiency, it is in the state of constant returns to scale. When returns to scale are in the state of decreasing, the enterprises are generally technical 
inefficiency. We should ensure the pure technical efficiency as well as the appropriate increase in scale efficiency

In conclusion, in a fixed macro environment, the author put forward countermeasures and suggestions on how to improve the efficiency of enterprises: appropriately expand the scale of assets, encourage the enterprises to achieve economies of scale; improve the level of human resources, enhance the core competitiveness of enterprises; reasonable control of the asset-liability ratio, strengthen financial management; improve the salary and other remuneration incentives.

As for the enterprise managers, it is necessary to implement incentives based on the basic needs of workers; use a variety means of rewards to meet the basic needs of employees, without being limited to absolutism of the wages decided the fate of personnel.

Foundation Item:This subject was supported by 2014 College of Guangxi scientific and technological research projects, general project: Empirical Research Analysis (DEA) the efficiency of logistics enterprises based on data envelopment (No.: YB2014351).

\section{References}

[1] China's logistics industry analysis report (2014). China Economic Information Network, http://www.cei.gov.cn/.

[2] Thomas, Landers, Michael H. The virtual warehousing concept [J] Transportation research Part, 2000, (36): $115 \sim 125$.

[3] Samuelson, Economics [M] Beijing: China Development Press, 1992, (5).

[4] http://218.26.207.140/encrypt/zx63/g1zz/20041107/chinese/2_02.htm.

[5] M.J.Farrell.The Measurement of Production Efficiency [J] .Journal of Royal Stutistical Society, Series A, 1957,120 (3): 253-281

[6] Fan Chunmei. Logistics Performance Evaluation Method and Empirical Analysis [D]. Changsha University master's degree thesis, 2005:

[7] 16 to 45 .

[8] Binshan Lin James Collins, Robert K. Su Supply Chain Costing:. An Activity-based Persective [J] .International Journal of Physical Distribution \& Logistics Management, 2001, (31): $702 \sim 713$.

[9] Ai Shengdong, Deng Xudong. Evaluation Based on Fuzzy Comprehensive Evaluation of High School Teaching Quality [J]. Scientific decision-making, 2008 (10): 48 